Article

\title{
Evaluating the Role of Geofoam Properties in Reducing Lateral Loads on Retaining Walls: A Numerical Study
}

\author{
Muhammad Imran Khan ${ }^{1,2}$ and Mohamed A. Meguid ${ }^{1, *(D)}$ \\ 1 Department of Civil Engineering, McGill University, 817 Sherbrooke St. W., Montreal, QC H3A 0C3, Canada; \\ muhammad.khan14@mail.mcgill.ca \\ 2 Department of Civil Engineering, University of Engineering and Technology, Lahore 54890, Pakistan \\ * Correspondence: mohamed.meguid@mcgill.ca
}

check for updates

Citation: Khan, M.I.; Meguid, M.A. Evaluating the Role of Geofoam Properties in Reducing Lateral Loads on Retaining Walls: A Numerical Study. Sustainability 2021, 13, 4754. https://doi.org/10.3390/su13094754

Academic Editor: Hany El Naggar

Received: 20 March 2021

Accepted: 22 April 2021

Published: 23 April 2021

Publisher's Note: MDPI stays neutral with regard to jurisdictional claims in published maps and institutional affiliations.

Copyright: (C) 2021 by the authors. Licensee MDPI, Basel, Switzerland. This article is an open access article distributed under the terms and conditions of the Creative Commons Attribution (CC BY) license (https:/ / creativecommons.org/licenses/by/ $4.0 /)$.

\begin{abstract}
Expanded polystyrene (EPS) geofoam is a lightweight compressible material that has been widely used in various civil engineering projects. One interesting application of EPS in geotechnical engineering is to reduce the lateral earth pressure on rigid non-yielding retaining walls. The compressible nature of the EPS geofoam allows for the shear strength of the backfill soil to be mobilized, which leads to a reduction in lateral earth pressure acting on the wall. In this study, a finite element model is developed and used to investigate the role of geofoam inclusion between a rigid retaining wall and the backfill material on the earth pressure transferred to the wall structure. The developed model was first calibrated using experimental data. Then, a parametric study was conducted to investigate the effect of EPS geofoam density, relative thickness with respect to the wall height, and the frictional angle of backfill soil on the effectiveness of this technique in reducing lateral earth pressure. Results showed that low-density EPS geofoam inclusion provides the best performance, particularly when coupled with backfill of low friction angle. The proposed modeling approach has shown to be efficient in solving this class of problems and can be used to model similar soil-geofoam-structure interaction problems.
\end{abstract}

Keywords: rigid retaining walls; isolation efficiency; finite element modeling; lateral earth pressure

\section{Introduction}

Expanded polystyrene (EPS) is a lightweight, closed cell, rigid foam material that is almost 100 times lighter than soil and 10-30 times lighter than other construction fill materials [1]. Horvath [2] first used the term "geofoam" for expanded polystyrene and recommended its addition to the geosynthetic category. Early application of EPS geofoam as engineering fill material started in the 1960s. The Norwegian geotechnical engineers, in 1965, used EPS geofoam in a road project for thermal insulation [3]. In 1972, EPS geofoam was used to construct embankments on soft soils [4]. Over the past 40 years, EPS geofoam has been successfully used in a variety of engineering projects, most of which have involved the use of molded blocks of EPS geofoam as light weight construction material for slope stabilization [5-9], subbase fill material [1,10-12], embankments on soft ground [10,13-17], earth retaining structures $[5,18]$, bridge approaches and abutments [5,19-23], and buried pipes $[5,24,25]$. The compressible nature of the EPS geofoam also encourages its use as a compressible inclusion [26-29].

Retaining structures are integral components of many important structures including bridges, ports, highways, railway, and underground structures. These retaining structures are typically designed to resist lateral earth pressure exerted by the surrounding soil mass. The design of a retaining wall is strongly related to the magnitude and distribution of earth pressure acting on the wall. The higher the earth pressure, the more the cost of the wall structure. Various methods have been suggested to reduce the magnitude of lateral earth pressure on retaining walls. Pressure reduction can be achieved by allowing controlled yielding of the backfill soil by introducing compressible material between the wall and 
backfill soil. Partos and Kazaniwsky [30] introduced EPS geofoam of low stiffness between a relatively higher stiffness retaining structure and the retained soil mass (see Figure 1). The least stiff material (EPS geofoam) generally compresses more than the other two materials, which causes reduction in the lateral earth pressure due to the mobilization of the shear strength within the adjacent soil [27].

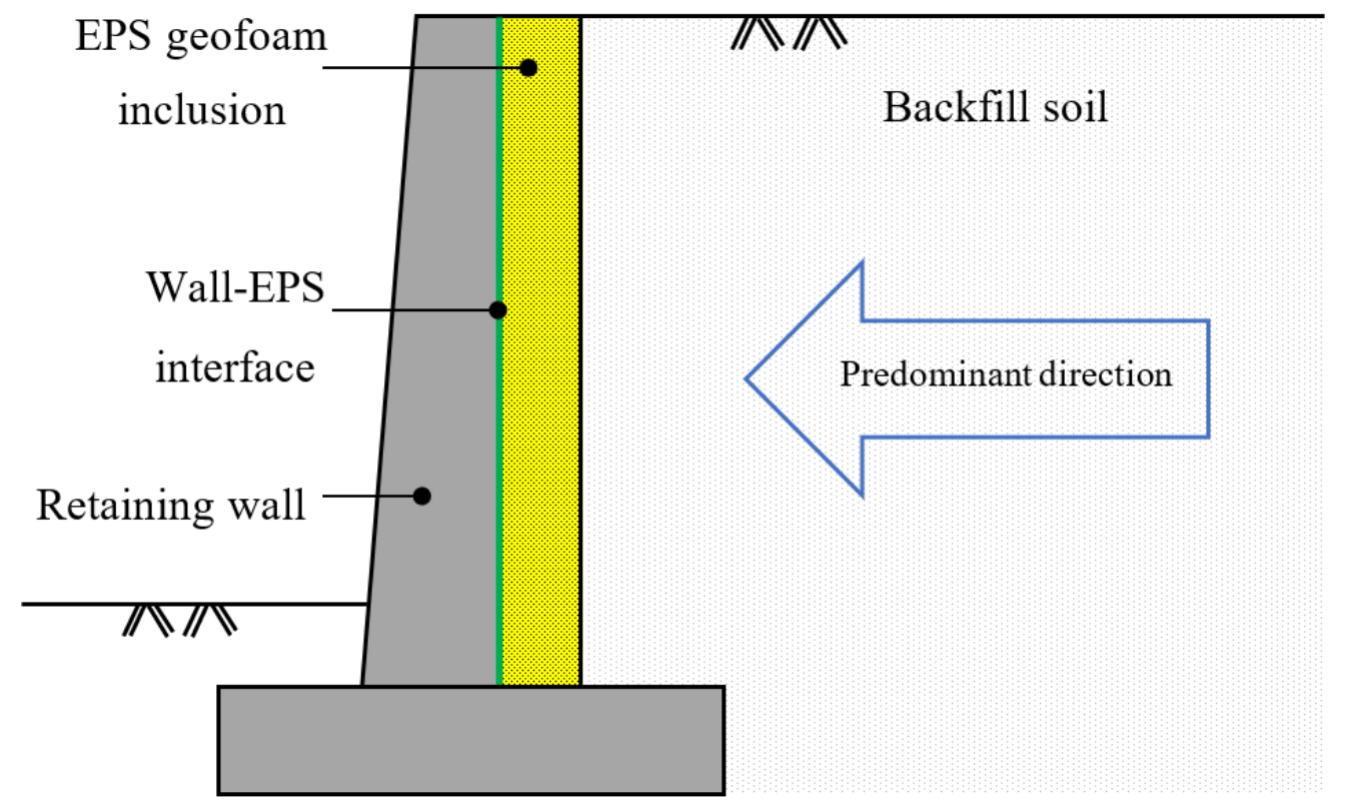

Figure 1. Use of expanded polystyrene (EPS) behind retaining walls.

Depending on the response of the earth retaining structures under the applied lateral loading, retaining walls can be broadly classified as follows: (i) Non-yielding retaining walls, when the structure is not allowed to displace or deform horizontally under the applied loads. These structures are typically designed based on at-rest earth pressure condition. (ii) Yielding retaining walls, when the structure is allowed to displace or deform horizontally under the applied load. Mostly, these structures are designed for active earth pressure condition. Compressible geofoam inclusion is generally more beneficial for non-yielding (rigid) retaining walls.

Researchers [30-35] have shown that the magnitude of the lateral loads on retaining walls can be reduced by installing a material of lower stiffness between the backfill soil and the wall structure, without increasing the wall stiffness. Partos and Kazaniwsky [30] reported a reduction in lateral earth pressure on a non-yielding basement wall by placing a prefabricated expanded polystyrene beaded drainage board between the wall and the granular backfill. Karpurapu and Bathurst [35] used numerical modeling to demonstrate that installing a geofoam layer with thickness that is equal to $1 \%$ of the wall height can bring the lateral earth pressure to a minimum level. Hatami and Witthoeft [36] extended the geofoam application to geosynthetic reinforced soil walls. Numerical results confirmed that the total forces that cause external sliding and overturning decreased by about $30 \%$ and 25\%, respectively. Trandafir et al. [37] concluded that the presence of EPS geofoam within the upper half of the wall can help with load reduction.

Ertugrul and Trandafir [34] studied the behavior of geofoam inclusion behind flexible walls. The results indicated that geofoam inclusion behind a retaining wall can cause a significant decrease in lateral thrust. This was attributed to the relative stiffness between the wall and the backfill material. Azzam and AbdelSalam [38] carried out a numerical analysis to investigate the performance of rigid yielding retaining walls with geofoam inclusion. The results showed that use of EPS significantly reduced the lateral pressure depending on the ratio between the EPS thickness and wall height. Chauhan and Dasaka [33] showed that geofoam inclusion could provide $8-42 \%$ reduction in lateral pressure for a surcharge 
of 10-50 kPa. Hasanpouri Notash and Dabiri [39] investigated the performance of geofoam in yielding and non-yielding retaining structures. The results showed that EPS geofoam performs better in non-yielding retaining walls. Yadav et al. [40] concluded that the presence of EPS geofoam reduces the pressure on retaining walls under both static and seismic condition.

It has been observed that limited numerical studies have been performed to simulate and expand the results of the available physical tests conducted on rigid non-yielding retaining walls under static conditions. In addition, in most of the reported studies, a few of the numerical results have been compared with measured data based on instrumented large-scale physical models. Therefore, this study is a step forward towards developing and validating a numerical model using experimental data and using the model to investigate the role of geofoam properties on the performance of rigid retaining structures.

This study focuses on the use of EPS geofoam in reducing lateral pressure on rigid non-yielding retaining walls. A two-dimensional finite element model is developed and validated using the experimental data reported by Ertugrul and Trandafir [41]. Then, a parametric study is performed to examine the role of relative thickness, stiffness of the EPS geofoam, and strength parameters of the backfill soil on the lateral earth pressure acting on rigid retaining wall. The results of this study are presented in the form of normalized charts covering a range of wall configurations and material properties.

\section{Description of the Physical Model}

Ertugrul and Trandafir [41] performed a series of experiments on a rigid non-yielding retaining wall with vertical EPS geofoam inclusion. A steel wall with dimensions $700 \times 980 \times 8 \mathrm{~mm}$ was firmly welded to a steel base $980 \times 500 \times 8 \mathrm{~mm}$ and hosted in a rigid container $2 \times 1 \times 1 \mathrm{~m}$. A schematic of the test setup and the locations of the pressure transducers (P1 to P4) are shown in Figure 2. Dry, clean sand was used as backfill material. Triaxial compression tests conducted on sand samples of relative density, $D_{r}$, of $70 \%$ indicated friction and dilatancy angles of $43.5^{\circ}$ and $22.5^{\circ}$, respectively. Blocks of EPS15 geofoam $\left(15 \mathrm{~kg} / \mathrm{m}^{3}\right)$ were installed between the wall and backfill. The properties of the sand and the EPS geofoam materials are summarized in Table 1.

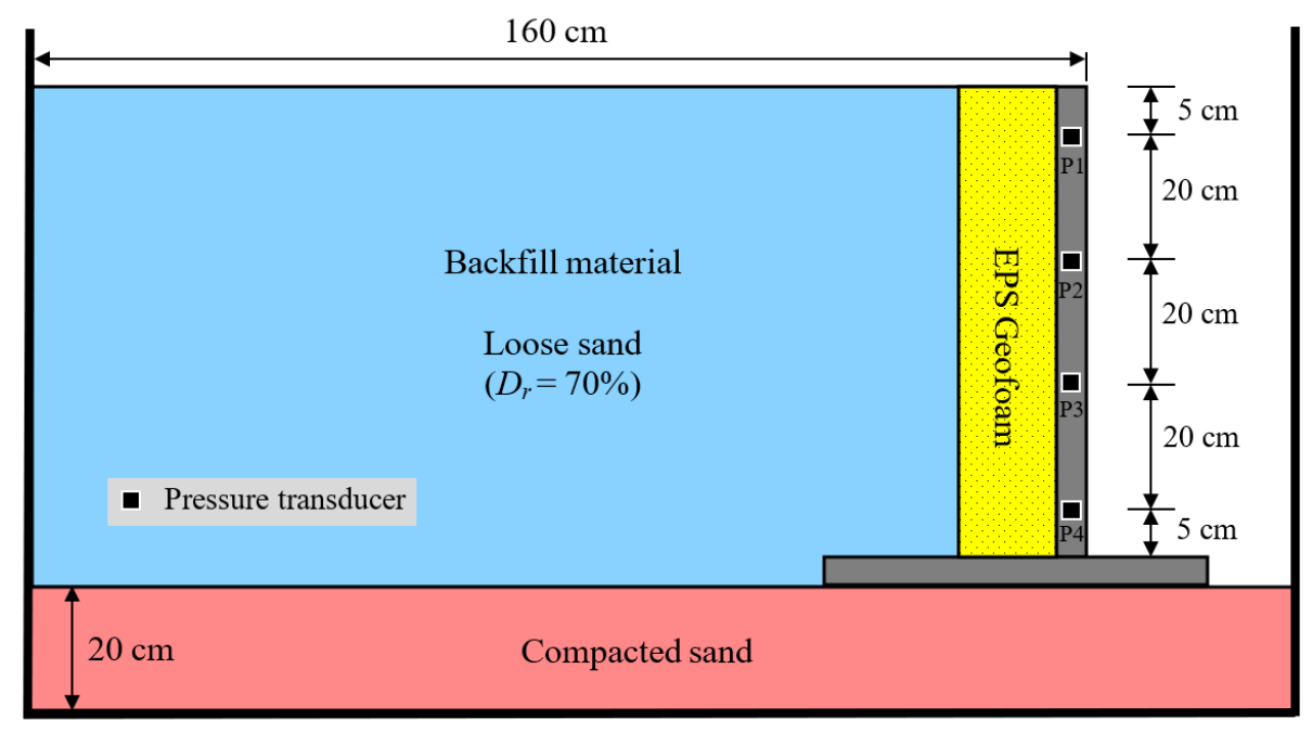

Figure 2. Geometry and configurations of the physical model (adapted from [41]). 
Table 1. Material properties used in the model validation [41].

\begin{tabular}{cccc}
\hline Property & Backfill Soil & Foundation Soil & EPS Geofoam \\
\hline Material model & Mohr-Coulomb & Mohr-Coulomb & Linear Elastic \\
Unit weight, $\gamma\left(\mathrm{kN} / \mathrm{m}^{3}\right)$ & 16.5 & 17.5 & 0.15 \\
Young's Modulus, $E\left(\mathrm{kN} / \mathrm{m}^{2}\right)$ & 5200 & 5500 & 1500 \\
Poisson's ratio, $v$ & 0.33 & 0.33 & 0.01 \\
Cohesion $c^{\prime}\left(\mathrm{kN} / \mathrm{m}^{2}\right)$ & 0.01 & 0.01 & - \\
Friction angle $\varphi^{\prime}($ degrees) & 43.5 & 22.5 & - \\
Dilatancy angle $\psi^{\prime}$ (degrees) & 22.5 & 0.29 & - \\
$K_{o}$ & 0.31 & - & - \\
Maximum void ratio & 0.745 & - & - \\
Minimum void ratio & 0.436 & - & - \\
Specific gravity & 2.66 & - & - \\
$c_{\mathcal{C}}$ (coefficient of curvature) & 0.80 & - & - \\
$c_{\mathcal{u}}$ (coefficient of uniformity) & 3.31 & - & - \\
Percent finer than \#200 sieve & 1.14 & & - \\
\hline
\end{tabular}

Experiments were conducted on four different wall configurations. In the first set of tests, lateral earth pressures were measured against the rigid wall with no geofoam inclusion, whereas the other sets of tests involved three different geofoam thicknesses that corresponded to $t / H$ ratios of $0.07,0.14$, and 0.28 , where $t$ is the geofoam thickness and $H$ is the wall height. The geofoam was placed behind the rigid retaining wall and the earth pressures were measured using four pressure transducers installed vertically along the wall height at $20 \mathrm{~cm}$ spacing, as shown in Figure 2.

\section{Numerical Analysis and Model Validation}

A two-dimensional finite element model was developed based on the experimental setup reported by Ertugrul and Trandafir [41]. The analysis was performed using the commercial software PLAXIS 2015 [42]. The retaining wall and the backfill material were modeled using 15-node triangular elements, as shown in Figure 3. Several element sizes were tested to find a suitable mesh that maintained the balance between accuracy and computation time. Smooth rigid boundary conditions were specified along the vertical boundaries, whereas rough rigid boundary conditions were specified along the base of the model. The backfill and foundation soil were both modeled as Mohr-Coulomb elastoplastic materials, whereas EPS geofoam was modeled as linear elastic material. Given that the EPS15 geofoam used in the experiments was subjected to a maximum horizontal pressure of about $3.6 \mathrm{kPa}$, which is much smaller than the yield stress $\left(\sigma_{y}=38 \mathrm{kPa}\right)$, the use of elastic material model for the geofoam is considered acceptable. Table 1 summarizes the material properties of both the soil and the EPS geofoam used in validating the numerical model. The retaining wall and its base were modeled as plate elements. The material properties of the wall and the base are given in Table 2.

The soil-wall, geofoam-wall, and soil-geofoam interfaces were modeled using MohrCoulomb elastoplastic interface elements. The interface friction angles were back calculated to match the experimental data. For the geofoam-wall, soil-geofoam, and soil-wall interfaces, the interface friction angles were found to be $16^{\circ}, 8^{\circ}$, and $5^{\circ}$, respectively. The EPS15 blocks of similar dimensions and material properties to those used in the experiments were adopted in the model with three different geofoam thicknesses that corresponded to $t / H$ ratios of $0.07,0.14$, and 0.28 .

The steps taken in modeling the retaining wall can be summarized as follows: (1) the foundation bed is first generated, (2) the wall and the base are activated, (3) the EPS blocks are introduced against the wall, (4) the backfill material is added in layers to reach the target height. 


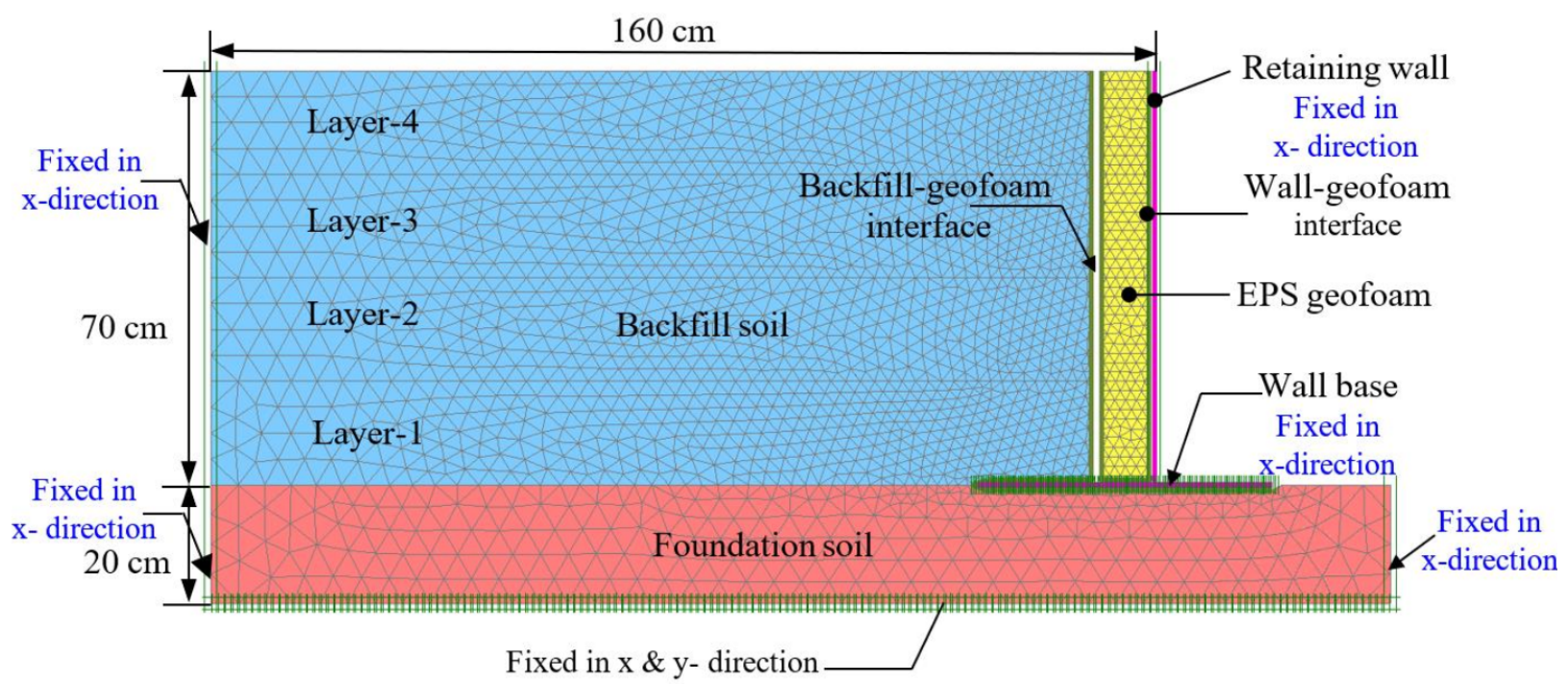

Figure 3. Finite element mesh of the rigid non-yielding retaining wall with geofoam inclusion.

Table 2. Material properties of the wall and the base.

\begin{tabular}{ccccc}
\hline \multirow{2}{*}{ Property } & \multicolumn{2}{c}{ Validated Model [34] } & \multicolumn{2}{c}{ Parametric Study } \\
\cline { 2 - 5 } & Wall & Wall Base & Wall & Wall Base \\
\hline $\begin{array}{c}\text { Material type } \\
\text { Normal stiffness, } \\
E A(\mathrm{kN} / \mathrm{m})\end{array}$ & Elastic, Isotropic & Elastic, Isotropic & Elastic, Isotropic & Elastic, Isotropic \\
$\begin{array}{c}\text { Flexural rigidity, } \\
E I\left(\mathrm{kN} \mathrm{m} \mathbf{m}^{2} / \mathrm{m}\right)\end{array}$ & $9.02 \times 10^{5}$ & $6.44 \times 10^{5}$ & $1.44 \times 10^{7}$ & $1.03 \times 10^{7}$ \\
$\quad$ Weight, $w$ & & & & \\
$(\mathrm{kN} / \mathrm{m} / \mathrm{m})$ & 0.67 & 6.87 & $4.40 \times 10^{2}$ & $4.40 \times 10^{2}$ \\
Poisson's ratio, $v$ & 0.25 & 0.62 & 2.49 & 2.49 \\
\hline
\end{tabular}

Four cases were numerically investigated starting with the reference model where no geofoam blocks were installed $(t / H=0)$.

The model validation results are presented in Figure 4, where the lateral earth pressure values, $\sigma_{h}$, are normalized with respect to the vertical pressure at the wall base $\left(\sigma_{v \text {-base }}=\gamma H=11.55 \mathrm{kPa}\right)$ and are plotted against the wall depth. For the four investigated cases, the calculated lateral pressures are compared with the experimental data. The results show that the numerical model is generally able to capture the pressure distribution with depth. This is particularly true for the case where no geofoam is installed, as represented by the solid line in Figure 4. For the cases where geofoam is placed behind the wall, the difference between the measured and the calculated stresses near the wall base is attributed to the interface friction that develops at the soil base as well as at the geofoam base. This in turn can lead to significant reduction in lateral pressures near the base of the wall.

For all investigated wall models, EPS geofoam experienced maximum horizontal stress, $\sigma_{\text {hmax }}$, of $2.5,2.0$, and $1.3 \mathrm{kPa}$ for $t / H$ of $0.07,0.14$, and 0.28 , respectively. This is found to be within the elastic limit of the used EPS15 geofoam, which has a compressive resistance of about $19 \mathrm{kPa}$ at $1 \%$ strain [41]. This also confirms the assumption of linear elastic response for the EPS geofoam under the applied loading. It is also found that the presence of geofoam inclusion behind the non-yielding retaining wall resulted in an arching effect within the lower half of the wall, which helped to absorb the majority of the lateral earth pressure acting on the wall. 


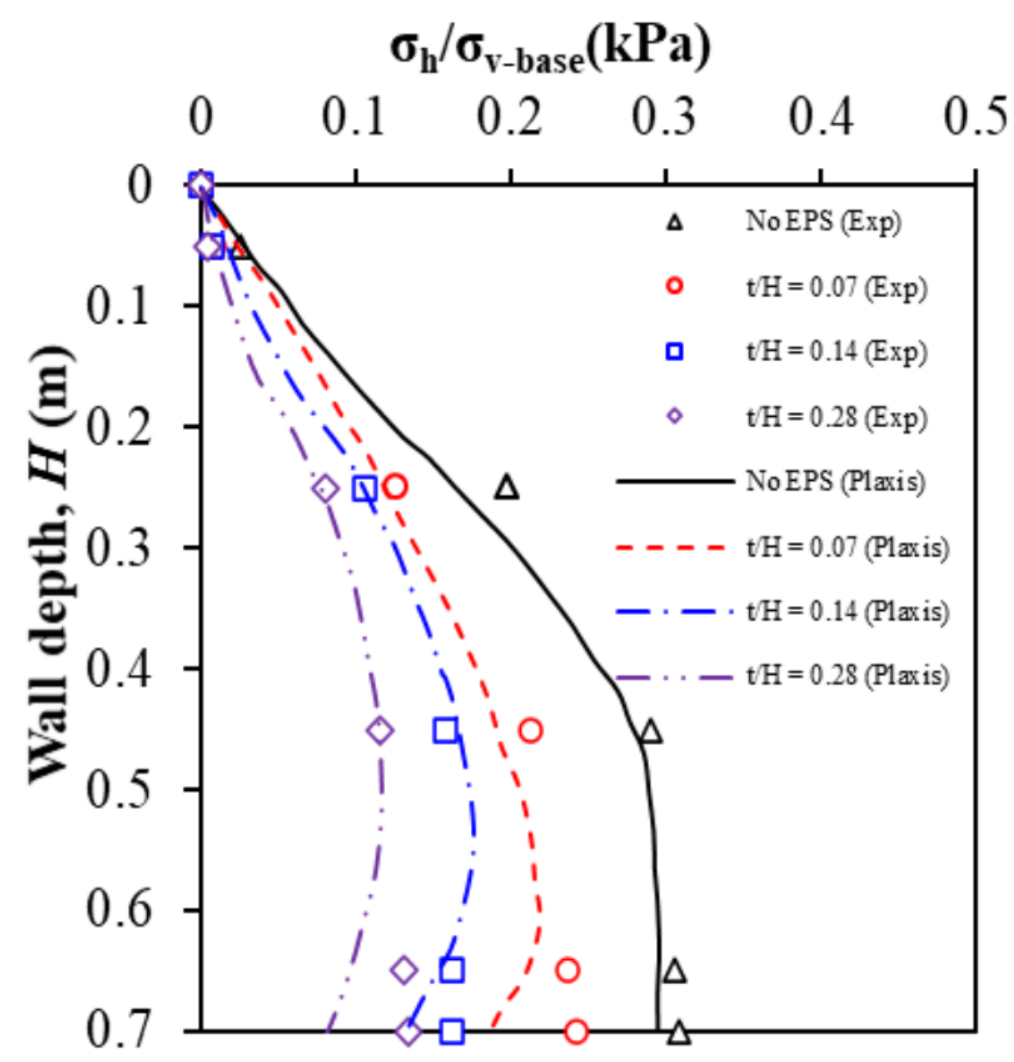

Figure 4. Normalized lateral earth pressures vs. wall depth.

The total thrust on the wall was calculated by computing the area under the pressure profile. The difference between the experimental data and the numerically calculated total lateral thrust was found to range between $5 \%$ and $9 \%$ for the four investigated cases.

\section{The Effect of Geofoam and Backfill Properties on the Lateral Earth Pressure Acting on the Wall}

A parametric study was conducted using a full-scale model to investigate the effect of geofoam density, thickness, and backfill friction angle $(\varphi)$ on the lateral earth pressure acting on the wall. A $2.80 \mathrm{~m}$ high retaining wall model was developed using 15-node plane strain triangular elements. A wall $(2800 \times 3920 \times 32 \mathrm{~mm})$ with rigid base $(3920 \times 2000 \times 32 \mathrm{~mm})$ was modeled using plate elements. The numerical parameters used to model the wall and the base are summarized in Table 2. The foundation and backfill soils were modeled using Mohr-Coulomb elastoplastic material model. In addition, Mohr-Coulomb elastoplastic interface elements were used at the wall-soil, wall-geofoam, and soil-geofoam interfaces. For the wall-geofoam, geofoam-soil, and wall-soil interfaces, a range of friction angles between $8^{\circ}$ and $22^{\circ}$ was used in the analysis to cover wide possibilities of contact properties.

Before conducting the parametric study, a convergence analysis was performed using different mesh sizes for three cases involving geofoam panels with relative thickness of $0.1,0.2$, and 0.3 with respect to the wall height. The calculated displacements at a depth of $2.4 \mathrm{~m}$ are presented in Figure 5. The results indicate that, depending on the thickness of the geofoam, the sensitivity of the response to the mesh size becomes insignificant when the number of nodes reaches about $28,000,30,000$, and 33,000 for $t / H$ of $0.1,0.2$, and 0.3 respectively. The properties of finite element meshes used in this study are summarized in Table 3.

Three different geofoam materials, namely EPS22, EPS29, and EPS39, of different relative thicknesses with respect to the wall height $(t / H=0,0.05,0.1,0.15,0.2,0.25$, and 0.3 ) were considered. The results of the uniaxial compressive strength tests performed on the three geofoam materials are depicted in Figure 6. For the three geofoam materials, 
with densities of 22,29 , and $39 \mathrm{~kg} / \mathrm{m}^{3}$, the reported compressive strength results at $1 \%$ strain are found to be 70,94, and $192 \mathrm{kPa}$, respectively. Given the expected range of lateral pressure (from 3 to $23 \mathrm{kPa}$ ), the geofoam materials are subjected to pressure levels that are within the linear elastic range. Material properties of both the soil and geofoam used in this parametric study are summarized in Table 4. It is worth noting that the material properties, aspect ratio, and boundary conditions used in the numerical model of the large-scale wall are similar to those used in the model validation shown in Figure 3.

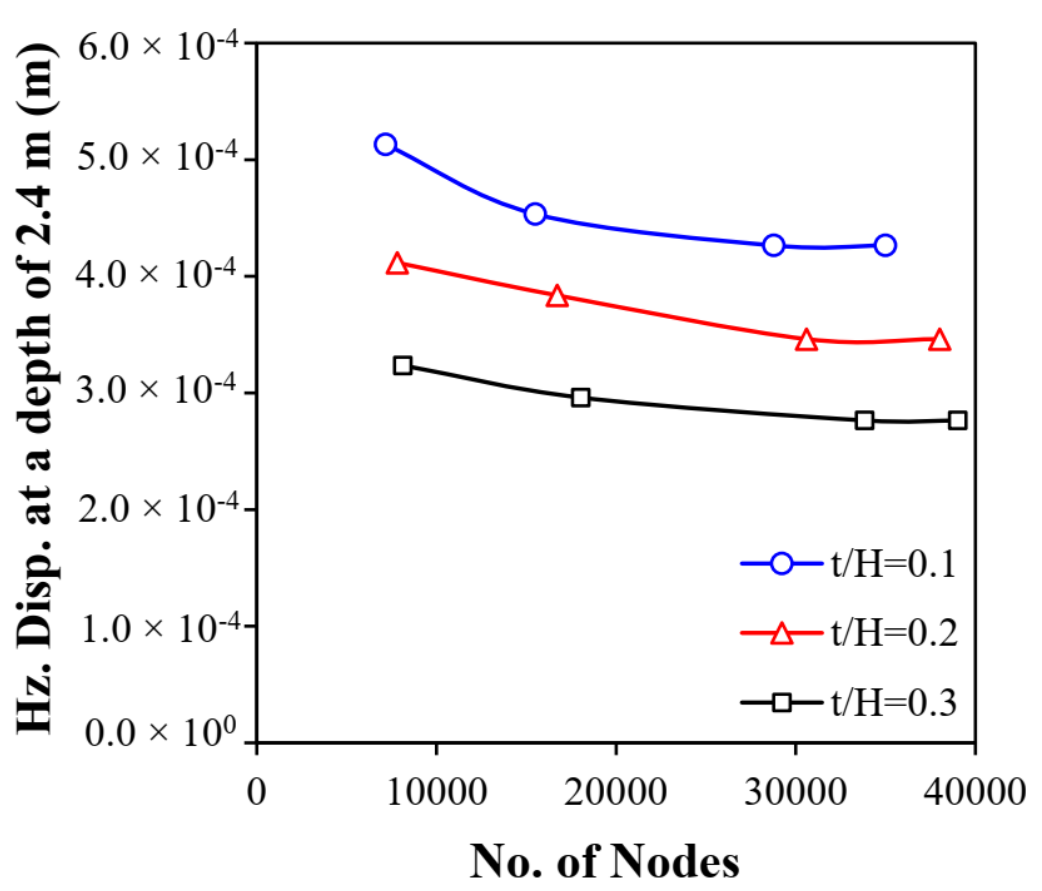

Figure 5. Convergence effect with variation in mesh size for geofoam thickness to wall height ratio $(t / H)=0.1,0.2$, and 0.3 .

Table 3. Properties of finite element meshes used in the analysis.

\begin{tabular}{cccc}
\hline Properties & $\boldsymbol{t} / \boldsymbol{H}=\mathbf{0 . 1}$ & $\boldsymbol{t} / \boldsymbol{H}=\mathbf{0 . 2}$ & $\boldsymbol{t} / \boldsymbol{H}=\mathbf{0 . 3}$ \\
\hline No. of soil elements & 3467 & 3693 & 4097 \\
No. of nodes & 28,777 & 30,597 & 33,825 \\
Average element size, $\mathrm{m}$ & 0.1222 & 0.1172 & 0.1116 \\
Maximum element size, $\mathrm{m}$ & 0.287 & 0.285 & 0.287 \\
Minimum element size, $\mathrm{m}$ & 0.044 & 0.03909 & 0.04576 \\
\hline
\end{tabular}

Table 4. Material properties used in the parametric study.

\begin{tabular}{cccccc}
\hline Property & Backfill Soil & Foundation Soil & EPS22 & EPS29 & EPS39 \\
\hline Material model & Mohr-Coulomb & Mohr-Coulomb & Linear Elastic & Linear Elastic & Linear Elastic \\
Unit weight, $\gamma\left(\mathrm{kN} / \mathrm{m}^{3}\right)$ & 16 & 17 & 0.22 & 0.29 & 0.39 \\
Young's Modulus, $E\left(\mathrm{kN} / \mathrm{m}^{2}\right)$ & 25,000 & 30,000 & 6910 & 10,000 & 178,000 \\
Poisson's ratio, $v$ & 0.33 & 0.33 & 0.12 & -13 & -15 \\
Cohesion $c^{\prime}\left(\mathrm{kN} / \mathrm{m}^{2}\right)$ & 0.01 & 0.01 & - & - & - \\
Friction angle $\varphi^{\prime}$ (degrees) & $30-45^{\circ}$ & 45 & - & - & - \\
Dilatancy angle $\psi^{\prime}$ (degrees) & 0 & 0 & - & - & - \\
$K_{o}$ & $0.29-0.50$ & 0.29 & & & - \\
\hline
\end{tabular}




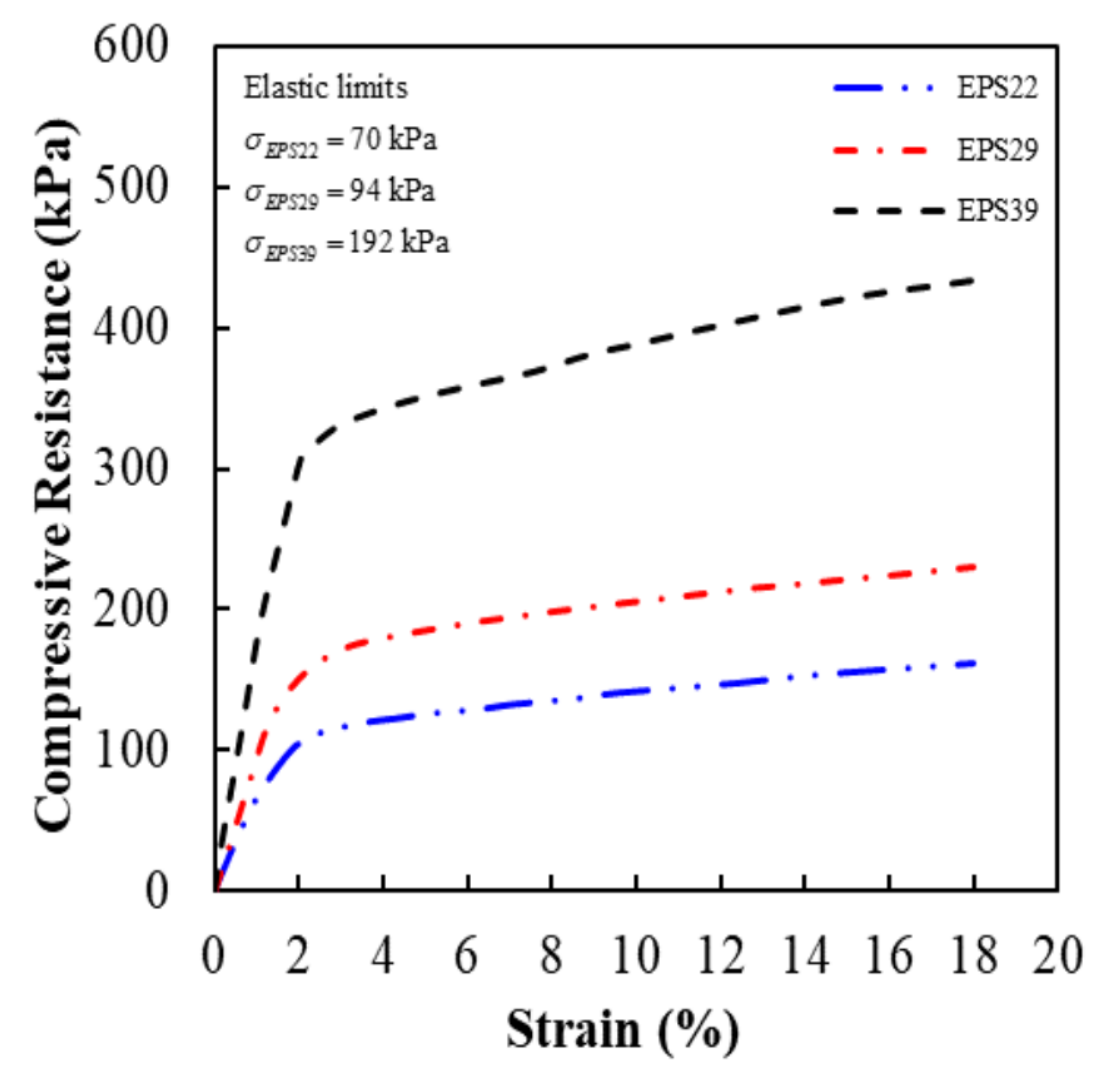

Figure 6. Stress-strain relationships of three geofoam materials, i.e., EPS22, EPS29, and EPS39.

\section{Results and Discussion}

The results of the numerical analysis are presented in this section by comparing the changes in horizontal pressure with depth for the benchmark case (no geofoam) with those obtained when geofoam blocks of different thicknesses and densities are installed. The calculated lateral earth pressure distributions with depth are presented using four sets of charts grouped in Figure $7 \mathrm{a}-\mathrm{c}$ for backfill material with friction angle of $30^{\circ}$; Figure $7 \mathrm{~d}-\mathrm{f}$ for backfill material with friction angle of $35^{\circ}$; Figure $7 \mathrm{~g}-\mathrm{i}$ for backfill material with friction angle of $40^{\circ}$; and Figure $7 \mathrm{j}-1$ for backfill material with friction angle of $45^{\circ}$. Three EPS densities are examined, namely 22,29 , and $39 \mathrm{~kg} / \mathrm{m}^{3}$. The relative thicknesses of the geofoam panels $t / H$ were chosen to cover a wide range of possibilities from a $t / H$ ratio of 0 (no geofoam) and increasing incrementally to 0.3 . Rankine's active earth pressure (R. AEP) and Jáky's [43] at-rest earth pressure (J. AREP) lines are also added to compare the theoretical value with those calculated using the numerical analysis. The effects of different parameters on the lateral pressure distribution on the wall for each case are presented under separate headings below. 

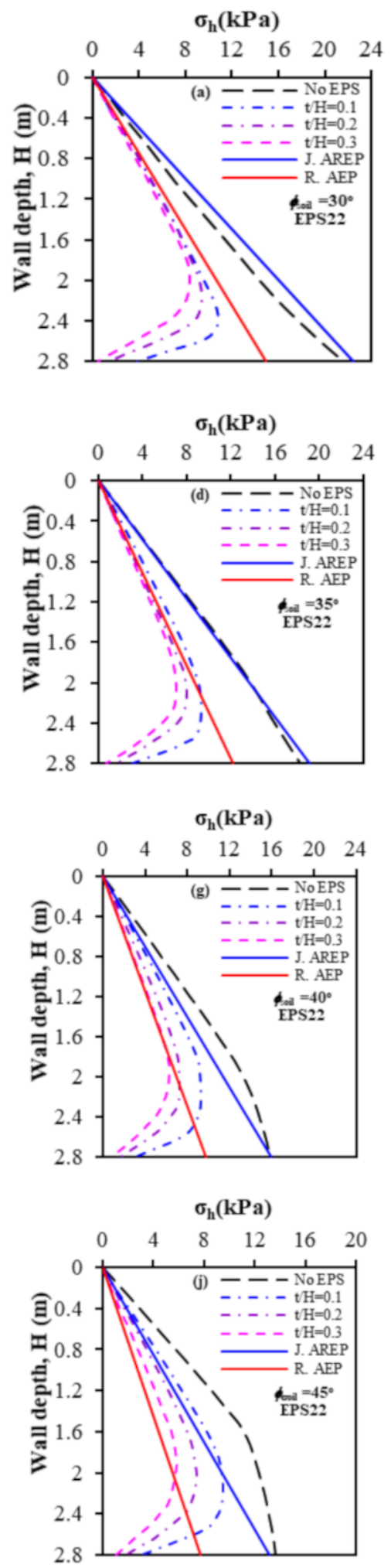
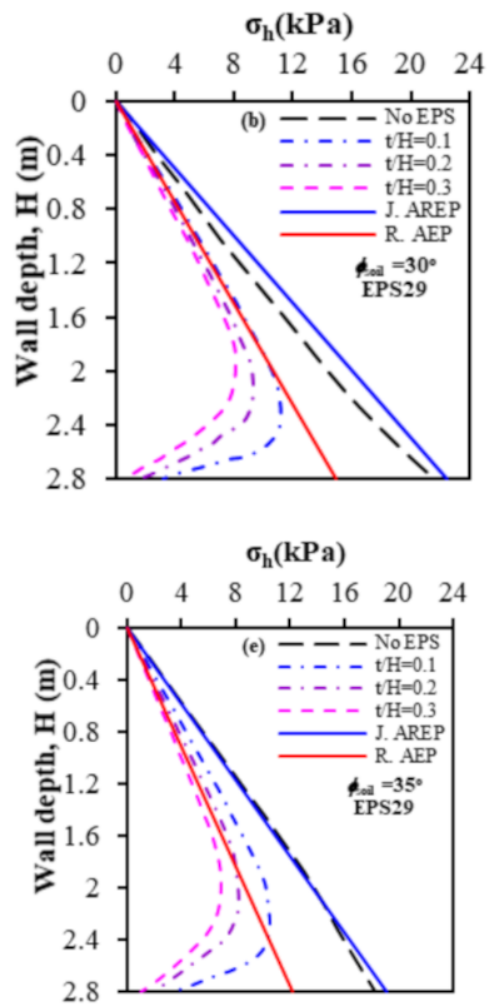

$\sigma_{\mathrm{h}}(\mathrm{kPa})$

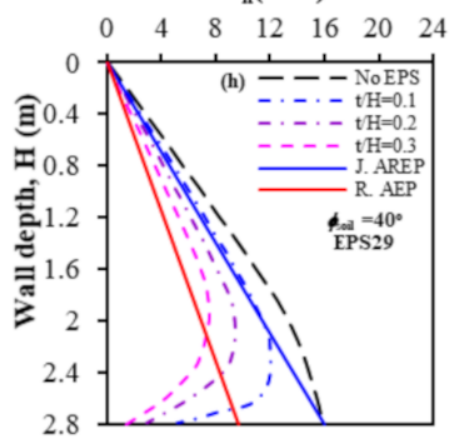

$\sigma_{\mathrm{h}}(\mathrm{kPa})$

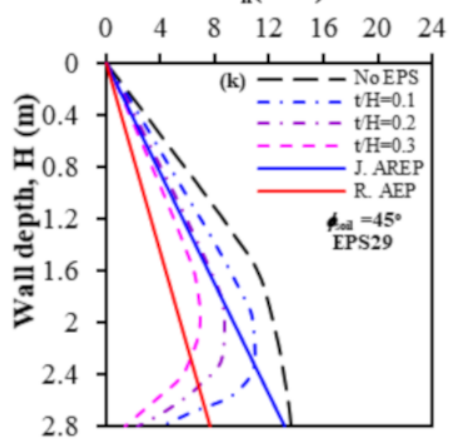

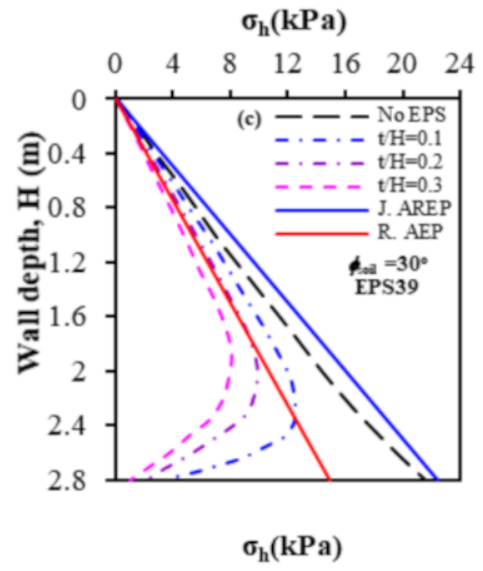

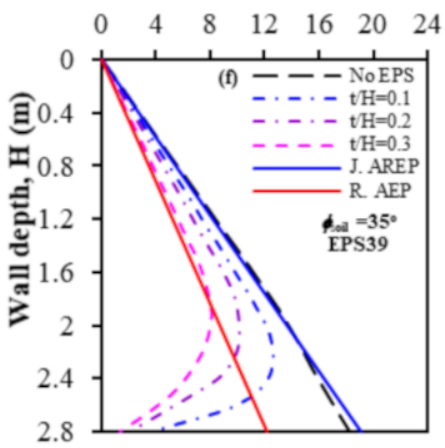

$\sigma_{\mathrm{h}}(\mathrm{kPa})$

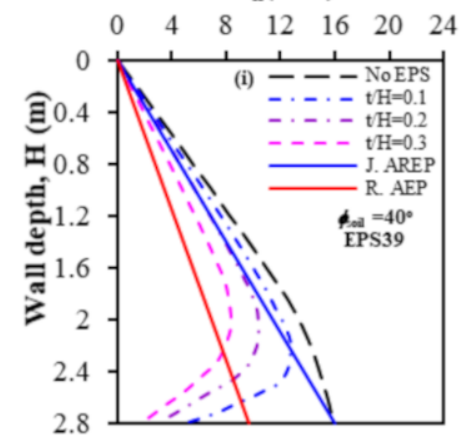

$\sigma_{\mathrm{h}}(\mathrm{kPa})$

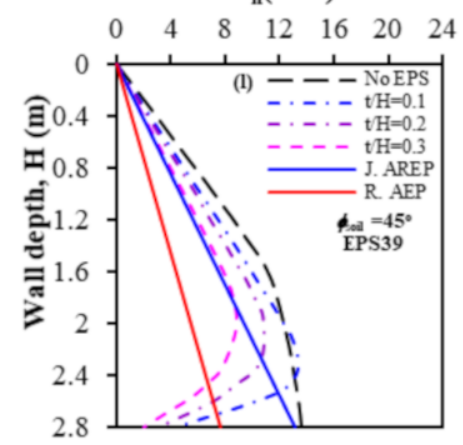

Figure 7. Lateral earth pressure distributions on walls for different geofoam densities and thicknesses: $(\mathbf{a}-\mathbf{c}) \varphi=30^{\circ} ;(\mathbf{d}-\mathbf{f}) \varphi$ $=35^{\circ} ;(\mathbf{g}-\mathbf{i}) \varphi=40^{\circ} ;(\mathbf{j}-\mathbf{1}) \varphi=45^{\circ}$.

\subsection{Benchmark Case (No Geofoam Inclusion)}

By inspecting the results in Figure 7a-f, it is evident that for backfill materials with lower friction angle values, $30^{\circ}$ and $35^{\circ}$, the calculated earth pressure distributions were generally found to linearly increase with depth consistent with that of the theoretical at-rest 
earth pressure (J. AREP) line. However, for backfill with higher friction angles of $40^{\circ}$ and $45^{\circ}$ (Figure $7 \mathrm{~g}-1$ ) the lateral pressure distributions change from linear to nonlinear near the middle of the wall.

As the friction angle increased from $30^{\circ}$ to $45^{\circ}$, the at-rest earth pressure coefficient decreased resulting in a decrease in lateral pressure from 22.4 to $13.4 \mathrm{kPa}$. This can be attributed to the frictional forces developing at the interface between the backfill and the base plate supporting the wall, which differs from the theoretical solution obtained for semi-infinite soil medium.

\subsection{Effect of Geofoam Density}

By inspecting Figure 7a-1, it is evident that for a given geofoam thickness and backfill properties, the density of the geofoam panel has significant effects on the lateral pressure acting on the wall. It was found that, for a given type of backfill material, geofoam of lower density absorbs more lateral movement and can bring the soil into an active or near active state as compared with higher density geofoam. For example, for $t / H=0.1$ and $\varphi_{\text {soil }}=30^{\circ}$, the maximum pressure decreased from $12.4 \mathrm{kPa}$ to $10.8 \mathrm{kPa}$ as the geofoam density decreased from $39 \mathrm{kN} / \mathrm{m}^{3}$ to $22 \mathrm{kN} / \mathrm{m}^{3}$. This is consistent with the fact that geofoam of lower density compresses more under the same applied lateral pressure resulting in more soil movement and, consequently, less pressure on the wall. This observation confirms that, for the investigated wall configuration and applied pressure levels, low density geofoams are considered to be effective in absorbing static lateral pressure and enhance the overall performance of the system.

\subsection{Effect of Geofoam Thickness}

For a given geofoam density and backfill material, the effect of geofoam thickness is examined in this section by plotting the lateral pressure results for different relative geofoam thickness $(t / H)$, as depicted in Figure 7a-l. Using geofoam panels of smaller $t / H$ value is found to absorb less soil movement as compared with the cases when thicker geofoam of the same density is used. For example, for a geofoam density of $22 \mathrm{~kg} / \mathrm{m}^{3}$ (EPS22) and $\varphi_{\text {soil }}=30^{\circ}$, the maximum earth pressure decreased from about 10.8 to $8.4 \mathrm{kPa}$ as the relative thickness of the geofoam $(t / H)$ increased from 0.1 to 0.3 . This is attributed to the fact that thicker geofoam can compress more under the same applied lateral pressure, which in turn produces more soil movement and less pressure on the wall. However, as increasing the thickness of the geofoam can result in adding more costs to the project, a balance is needed between the additional cost of the geofoam material and the design benefits associated with the reduction in lateral earth pressure on the wall.

\subsection{Effect of Friction Angle of Backfill Soil}

The magnitude of lateral earth pressure is found to be also influenced by the friction angle of the backfill soil, $\varphi_{\text {soil }}$. Soil with a high friction angle value exerts less pressure on the retaining wall due to a smaller coefficient of active earth pressure. As shown in Figure 7a-l, soils with smaller friction angle values induced more lateral pressure as compared to those with higher friction angle values for the same geofoam density and thickness. For example, for geofoam with density of $22 \mathrm{~kg} / \mathrm{m}^{3}$ (EPS22) and $t / H=0.1$, soil with $\varphi_{\text {soil }}=30^{\circ}$ corresponded to $38 \%$ reduction in pressure while soil with $\varphi_{\text {soil }}=45^{\circ}$ corresponded to a $28 \%$ reduction in lateral earth pressure. This indicates that the use of EPS geofoam inclusion is effective in soils that have lower friction angle values.

It is important to mention that although the presence of geofoam inclusion behind rigid retaining walls caused a reduction in lateral earth pressure, there exist a limiting combination of geofoam density and relative thickness of the geofoam $(t / H)$ to achieve active state, which depends on the frictional properties of backfill material, as depicted in Figure 7a-1. For example, for backfill with $\varphi_{\text {soil }}=40^{\circ}$, active condition can be achieved using $t / H=0.1$ for EPS22, $t / H=0.2$ for EPS29, or $t / H=0.3$ for EPS39. Therefore, depending on the frictional properties of the backfill material and the tolerable pressure on the retaining 
wall, a suitable geofoam density along with required $t / H$ value may be selected to achieve active or near active conditions in the backfill.

\subsection{Isolation Efficiency $\left(I_{E}\right)$}

Another way to evaluate the performance of EPS inclusion is by expressing the results in terms of isolation efficiency. Isolation efficiency $\left(I_{E}\right)$ is defined as "the ratio of the difference between the total lateral thrust on the wall before and after introducing the geofoam $\left(T_{0}-T_{E P S}\right)$ divided by $T_{o}$ " and can be calculated as follows:

$$
I_{E}=\frac{T_{o}-T_{E P S}}{T_{o}} \times 100
$$

The total lateral thrust acting on the wall can be computed using the following equation:

$$
T=\int_{0}^{H} \sigma_{x} d_{z}
$$

where $T$ is the total lateral thrust acting on the wall, $\sigma_{x}$ is the lateral earth pressure, and $H$ is the wall height. Figure 8 shows the effects of density and relative thickness of the geofoam and the frictional properties of the soil on the isolation efficiency. The results show that for the investigated four soil types, the isolation efficiency increases with an increase in the relative geofoam thickness. It was also found that the isolation efficiency increased with a reduction in the friction angle of the backfill material. For example, for geofoam density of $22 \mathrm{~kg} / \mathrm{m}^{3}$ (EPS22) and $t / \mathrm{H}$ of 0.1 , the isolation efficiency decreased from $38 \%$ to $28 \%$ as the friction angle of the backfill soil increased from $30^{\circ}$ to $45^{\circ}$. This is due to the fact that higher friction angles $\left(\varphi_{\text {soil }}\right)$ correspond to a smaller at-rest earth pressure coefficient, which induces smaller lateral pressures on the geofoam and the wall. The maximum isolation efficiency is achieved with EPS22 for backfill soil with $\varphi_{\text {soil }}=30^{\circ}$, whereas the minimum value of isolation efficiency is obtained with EPS39 for backfill soil having $\varphi_{\text {soil }}=45^{\circ}$. This response is consistent with an increase in the material stiffness associated with an increase in the geofoam density [44-46].
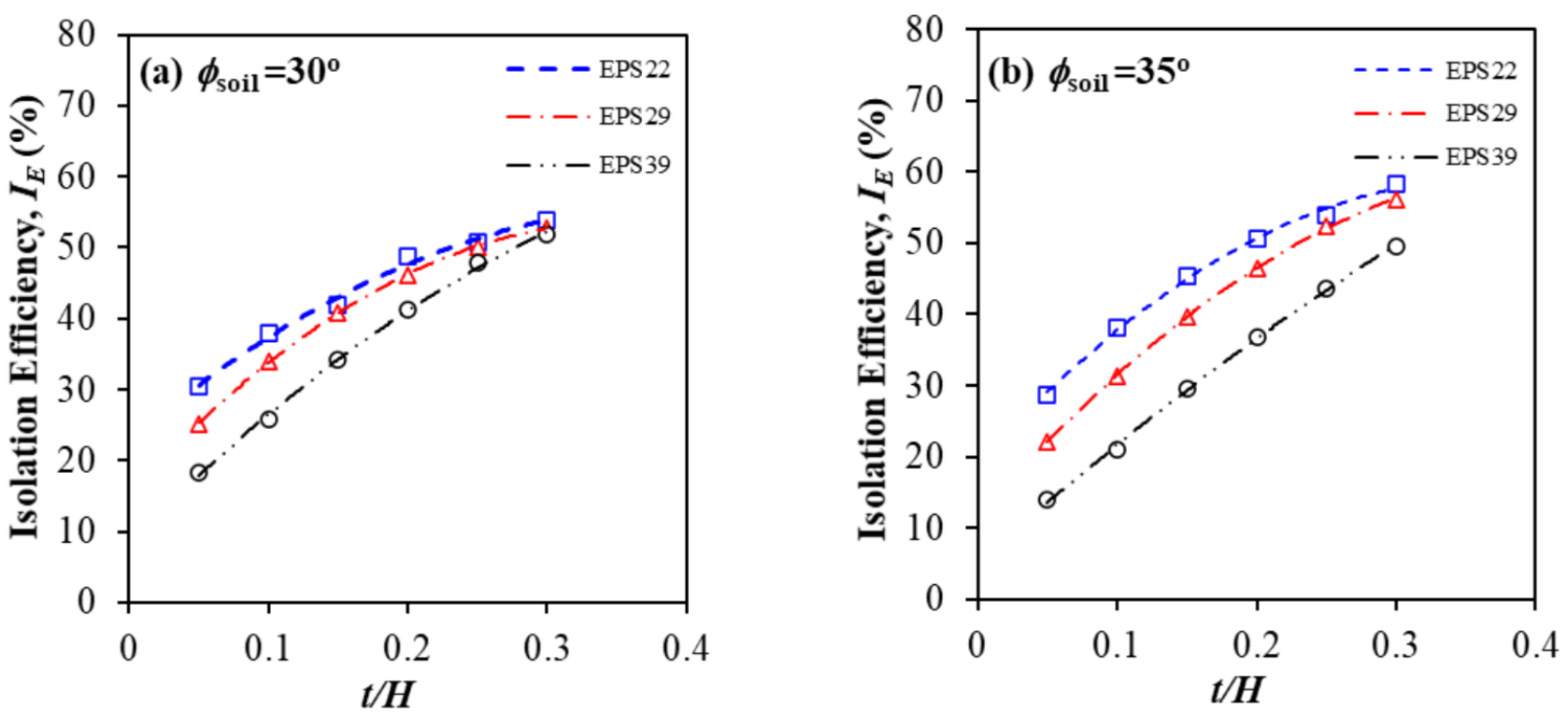

Figure 8. Cont. 

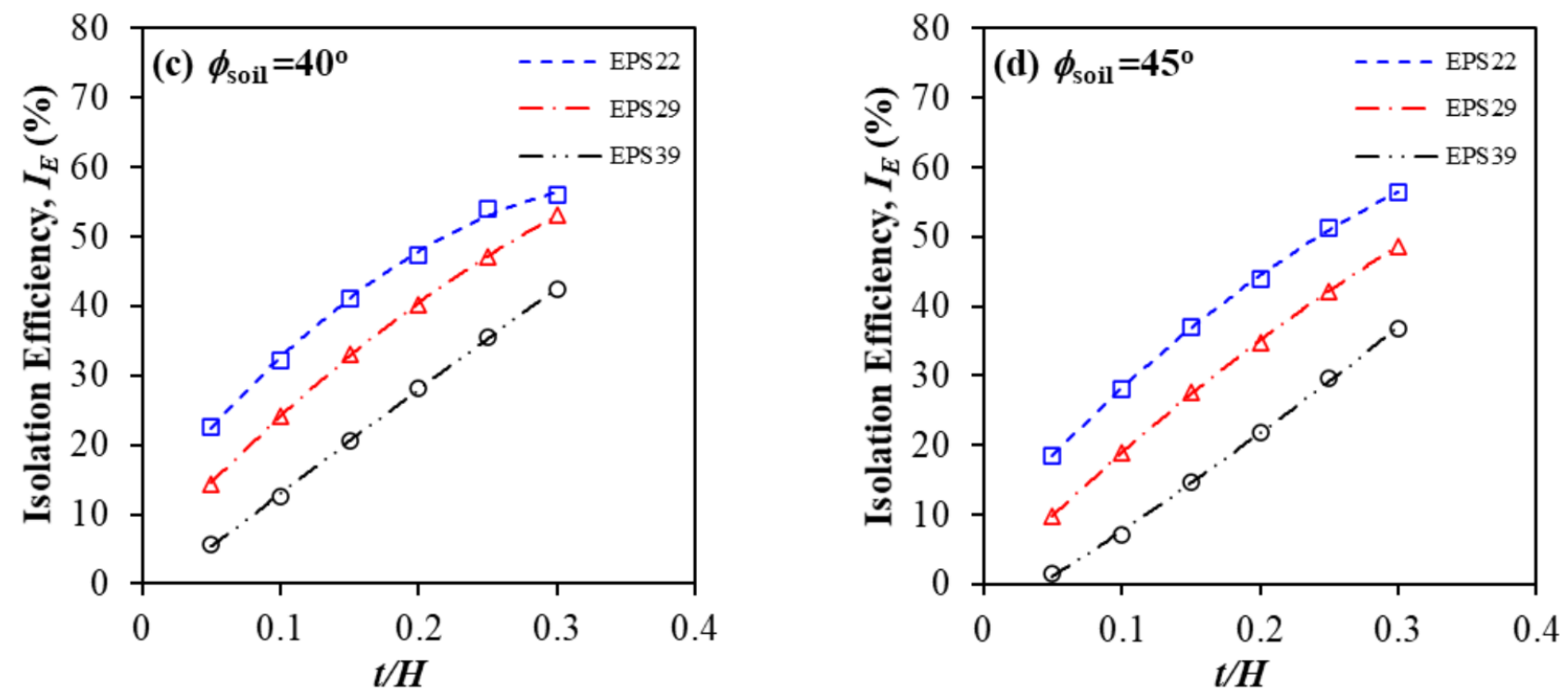

Figure 8. Isolation efficiency vs. $t / H$ for EPS22, EPS29, and EPS39. (a) $\varphi=30^{\circ} ;$ (b) $\varphi=35^{\circ} ;$ (c) $\varphi=40^{\circ}$; (d) $\varphi=45^{\circ}$.

\subsection{Lateral Earth Pressure Coefficient Ratio}

The lateral earth pressures obtained from the numerical models were used to back calculate the coefficient of lateral earth pressure $K_{F E M}$ based on following equation:

$$
K_{F E M}=\frac{2}{\gamma H^{2}} \int_{0}^{H} \sigma_{x} d_{z}
$$

where $\gamma$ is the unit weight of soil, $\sigma_{x}$ is lateral earth pressure, and $H$ is the wall height. Then, the $K_{F E M}$ values were normalized using Rankine active earth pressure coefficient, $K_{a}$, and presented in Figure 9.
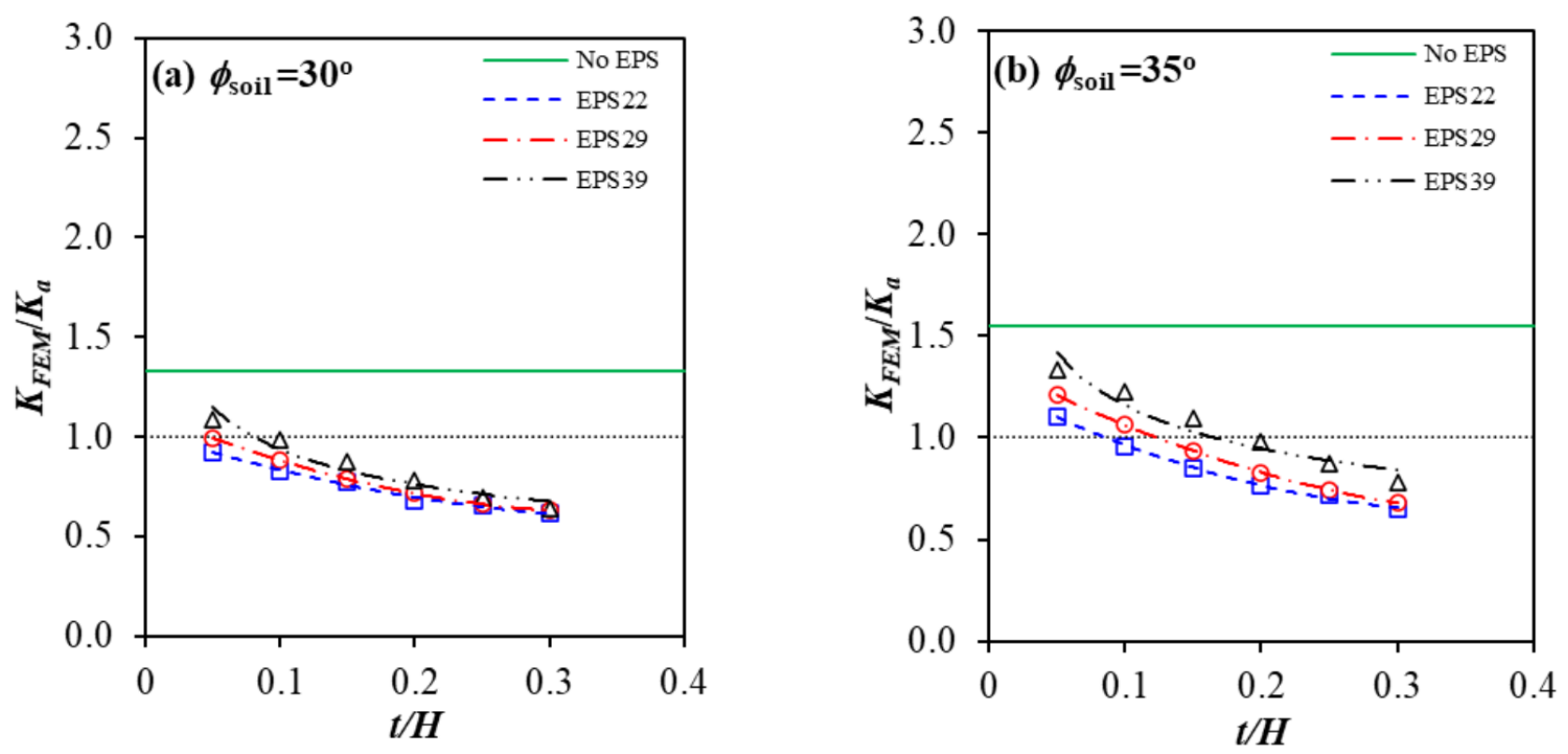

Figure 9. Cont. 

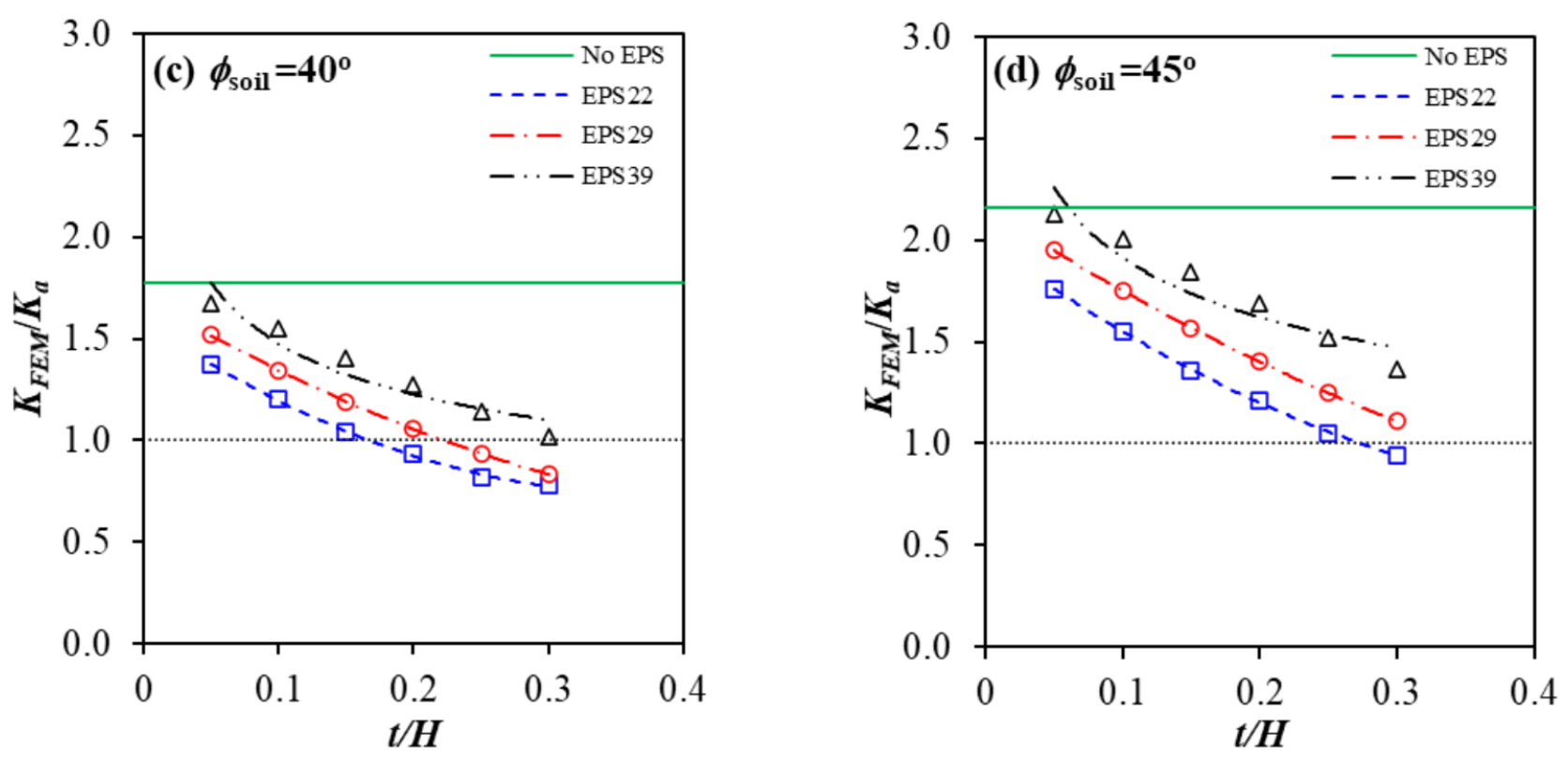

Figure 9. Variation of lateral earth pressure coefficient ratio $K_{F E M} / K_{a}$ ratio for various $t / H$, EPS, and backfill $\varphi$. (a) $\varphi=30^{\circ}$; (b) $\varphi=35^{\circ}$; (c) $\varphi=40^{\circ}$; (d) $\varphi=45^{\circ}$.

Figure $9 \mathrm{a}-\mathrm{d}$ show the change in lateral earth pressure coefficient ratio $\left(K_{F E M} / K_{a}\right)$ with the change in the relative thickness of the geofoam $(t / H)$ for the three investigated densities of geofoam, 22, 29, and $39 \mathrm{~kg} / \mathrm{m}^{3}$ and the four different backfill soils $\left(\varphi_{\text {soil }}=30^{\circ}, 35^{\circ}, 40^{\circ}\right.$, and $\left.45^{\circ}\right)$. A $K_{F E M} / K_{a}$ ratio of less than 1 means that the lateral earth pressure values are less than the corresponding Rankine's active earth pressure. In addition, for a given soil friction angle, a decreasing trend in $K_{F E M} / K_{a}$ ratio with an increase in $t / H$ indicates a better geofoam performance. For example, for $\varphi_{\text {soil }}=30^{\circ}$, maximum performance is achieved with EPS22 at $t / H=0.3$ where the $K_{F E M} / K_{a}$ ratio is minimum.

It is important to note that an increasing trend in $K_{F E M} / K_{a}$ ratio with an increase in friction angle should not be interpreted as " $K_{F E M}$ increases with an increase in friction angle $\left(\varphi_{\text {soil }}\right)^{\prime \prime}$. This is due to the fact that $K_{a}$ is not constant for the four investigated backfill soils $\left(\varphi_{\text {soil }}=30^{\circ}, 35^{\circ}, 40^{\circ}\right.$, and $\left.45^{\circ}\right)$ as $K_{a}$ decreases with an increase in friction angle.

\subsection{Horizontal Displacement in Backfill Soil}

Figure 10a-d present the effect of geofoam density, relative thickness, and backfill properties on the horizontal displacement obtained in the backfill soil. It is found that for a given backfill soil, the horizontal displacement increases with an increase in $t / H$ ratio and decreases with an increase in geofoam density. Moreover, for backfill with different frictional properties, horizontal displacement decreases with an increase in friction angle. For example, for a soil with $\varphi_{\text {soil }}=30^{\circ}$, geofoam density of $22 \mathrm{~kg} / \mathrm{m}^{3}$, the horizontal displacement decreased from $1.34 \mathrm{~mm}$ to $0.23 \mathrm{~mm}$ as $t / H$ decreased from 0.3 to 0.05 . This is due to the fact that thicker geofoam inclusion allows for more mobilization of the soil strength as compared with geofoam of reduced thickness. The maximum horizontal displacement $(1.34 \mathrm{~mm})$ is achieved for the case of EPS22 and $\varphi_{\text {soil }}$ of $30^{\circ}$, whereas the minimum horizontal displacement $(0.24 \mathrm{~mm})$ is achieved for the case of EPS39 and $\varphi_{\text {soil }}$ of $45^{\circ}$. 

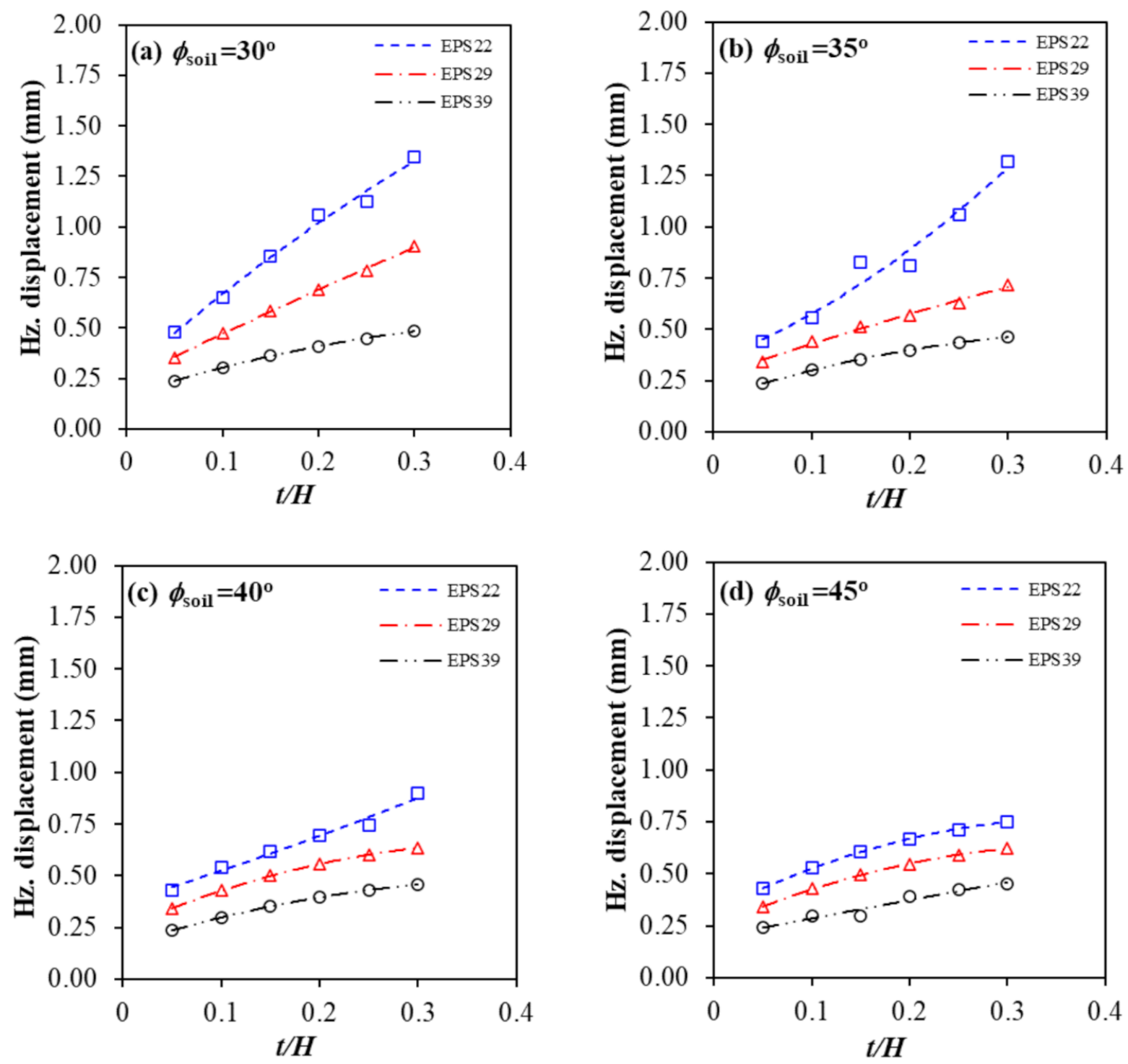

Figure 10. Horizontal displacement of backfill soil vs. $t / H$ for EPS22, EPS29, and EPS39. (a) $\varphi=30^{\circ}$; (b) $\varphi=35^{\circ} ;(\mathbf{c}) \varphi=40^{\circ}$; (d) $\varphi=45^{\circ}$.

\subsection{Practical Implications}

The results of this parametric study suggest that the isolation efficiency, $I_{E}$, associated with a case of geofoam inclusion behind a rigid wall depends on the used geofoam density and thickness and the frictional properties of the backfill material. Therefore, the normalized charts presented in this study can help for the preliminary assessment of the various design options that could guide engineers in their design. The charts presented in Figure 8 can be easily adapted and used to select a suitable geofoam density and thickness to achieve a specific isolation efficiency. To illustrate this procedure, an example is given below as follows:

For $H=4.0 \mathrm{~m}, \varphi_{\text {soil }}=35^{\circ}, I_{E}=40 \%$, and EPS22 geofoam, the thickness, $t$, of the geofoam can be found as follows:

$$
\begin{gathered}
\text { For } I_{E}=40 \% \\
\frac{t}{H}=0.118 t=0.118 \times H t=0.118 \times 4 t=0.472 \mathrm{~m}=47.2 \mathrm{~cm}
\end{gathered}
$$

Therefore, the nominal EPS geofoam thickness $(t)$ that satisfies $40 \%$ reduction in pressure is $47 \mathrm{~cm}$. 


\section{Conclusions}

In the present study, the effect of EPS geofoam inclusion on a rigid non-yielding retaining wall is numerically investigated using plane strain finite element modeling. Experimental data obtained using controlled laboratory tests were used to validate the numerical model. Then, a parametric study was performed to examine the effects of EPS geofoam density and relative thickness and the properties of the backfill soil on reducing the lateral earth pressure acting on a non-yielding retaining wall. The investigated parameters included three different geofoam densities and thickness interacting with four different backfill soils. The following conclusions can be drawn from this study:

1. Geofoam inclusion placed vertically behind rigid non-yielding retaining walls can allow the backfill soil to move towards the wall. This deformation helps in mobilization the soil shear strength leading to a reduction in lateral earth pressure acting on the wall.

2. The response of the granular backfill soil in these applications can be reasonably predicted using a Mohr-Coulomb elastoplastic material model, whereas a linear elastic model is found to be suitable for the geofoam material.

3. Relative thickness and density of the EPS geofoam and the frictional properties of the backfill material are found to play major roles in the magnitude of the isolation efficiency. It is also found that low density geofoam can provide better performance as compared with higher density material. For the same geofoam density, the thickness of the geofoam inclusion is found to have an effect on the geofoam compression. It is also found that EPS geofoam inclusions are more effective in soils with relatively low friction angles.

4. It is noted that possible long term creep effect of the geofoam is not considered in this study and the results are applicable to rigid non-yielding retaining walls supporting dry backfill.

Author Contributions: Analysis, writing original draft, M.I.K.; editing and reviewing, M.A.M. All authors have read and agreed to the published version of the manuscript.

Funding: Other than the graduate scholarship awarded to M.I. Khan, this research received no external funding.

Institutional Review Board Statement: Not applicable.

Informed Consent Statement: Not applicable.

Data Availability Statement: The data that support the findings of this study are available on request from the corresponding author.

Acknowledgments: The work presented in this paper is substantially supported by McGill University, Canada and the University of Engineering and Technology, Lahore, Pakistan. Geofoam data was provided by Plasti-Fab Inc., Calgary, Canada, their contribution is appreciated.

Conflicts of Interest: The authors declare no conflict of interest.

\section{References}

1. Stark, T.D.; Arellano, D.; Horvath, J.S.; Leshchinsky, D. Geofoam applications in the design and construction of highway embankments. Nchrp Web Doc. 2004, 65, 11-24.

2. Horvath, J.S. New developments in geosynthetics; 'lite' products come of age. Stand. News 1992, 20, 50-53.

3. Aaboe, R. Evidence of EPS Long Term Performance and Durability as a Lightweight Fill; Intern rapport No. 2139; Norwegian Public Roads Administration: Oslo, Norway, 2000.

4. Frydenlund, T. Expanded Polystyrene: A Lighter Way across Soft Ground; ICON Group International: San Diego, CA, USA, 1991; Volume 1502.

5. Elragi, A.F. Selected Engineering Properties and Applications of EPS Geofoam. Ph.D. Thesis, State University of New York College of Environmental Science and Forestry, New York, NY, USA, 2000.

6. Jutkofsky, W.; Sung, J.; Negussey, D. Stabilization of embankment slope with geofoam. Transp. Res. Rec. J. Transp. Res. Board 2000, 1736, 94-102. [CrossRef]

7. Sheeley, M. Slope Stabilization Utilizing Geofoam. Master's Thesis, Syracuse University, New York, NY, USA, 2000. 
8. Srirajan, S. Recycled Content and Creep Performance of EPS Geofoam in Slope Stabilization. Ph.D. Thesis, Syracuse University, New York, NY, USA, 2001.

9. Negussey, D. Slope Stabilization with Geofoam; Report to FHWA and the EPS industry; Geofoam Research Center, Syracuse University: New York, NY, USA, 2002.

10. Duskov, M. Use of expanded polystyrene (EPS) in flexible pavements on poor subgrades. In Proceedings of the International Conference on Geotechnical Engineering for Coastal Development, Port and Harbour Research Institute, Yokosuka, Japan, 3-6 September 1991; pp. 783-788.

11. Duskov, M. Measurements on a flexible pavement structure with an EPS geofoam sub-base. Geotext. Geomembr. 1997, 15, 5-27. [CrossRef]

12. Riad, H.L.; Ricci, A.L.; Osborn, P.W.; Horvath, J.S. Expanded polystyrene (EPS) geofoam for road embankments and other lightweight fills in urban environments. In Proceedings of the Soil and Rock America, 12th Pan-American Conference on Soil Mechanics and Geotechnical Engineering and 39th US Rock Mechanics Symposium, Cambridge, MA, USA, $22-26$ June 2003.

13. Refsdal, G. Plastic Foam in Road Embankments: Future Trends for EPS Use; Internal Report; Norwegian Road Research Laboratory: Oslo, Norway, 1985.

14. Aaboe, R. 13 years of experience with expanded polystyrene as a lightweight fill material in road embankments. Nor. Road Res. Lab. Publ. 1987, 61, 21-27.

15. Zou, Y.; Leo, C.; Small, J. Behaviour of EPS geofoam as flexible pavement subgrade material in model tests. Geosynth. Int. 2000, 7 , 1-22. [CrossRef]

16. Negussey, D.; Stuedlein, A.; Bartlett, S.; Farnsworth, C. Performance of a geofoam embankment at 100 South, I-15 reconstruction project, Salt Lake City, Utah. In Proceedings of the 3rd International Conference on EPS Geofoam, Salt Lake City, UT, USA, December 2001.

17. Farnsworth, C.; Bartlett, S.F.; Negussey, D.; Stuedlein, A. Rapid construction and settlement behavior of embankment systems on soft foundation soils. J. Geotech. Geo Environ. Eng. 2008, 134, 289-301. [CrossRef]

18. Frydenlund, T.; Aaboe, R. Expended polystyrene-the lightweight solution. In Proceedings of the International Symposium on EPS Construction Method (EPS-Tokyo'96), Tokyo, Japan, 29-30 October 1996; pp. 31-46.

19. Williams, D.; Snowdon, R. A 47 Great Yarmouth Western Bypass: Performance during the First Three Years (No. 11); Transport and Road Research Laboratory (TRRL): Berkshire, UK, 1990.

20. Skuggedal, H.; Aaboe, R. Temporary overpass bridge founded on expanded polystyrene. In Proceedings of the 1st European Conference on Soil Mechanics and Foundation Engineering, Florence, Italy, 2 May 1991; pp. 559-561.

21. McDonald, P.; Brown, P. Ultra lightweight polystyrene for bridge approach fill. In Proceedings of the 11th Southeast Asian Geotechnical Conference, Singapore, 4-8 May 1993; pp. 664-668.

22. Bang, S. Experimental and analytical study of expanded polystyrene blocks in highway application. In Proceedings of the International Seminar on the Application of EPS for Embankment Construction, Korea Institute of Construction Technology (KICT), Seoul, Korea, 1995; pp. 105-133.

23. Abu-Hejleh, N.; Zornberg, J.G.; Elias, V.; Watcharamonthein, J. Design assessment of the founders/meadows GRS abutment structure. In Proceedings of the 82nd Annual TRB Meeting, Washington DC, USA, 12-16 January 2003.

24. Meguid, M.; Hussein, M.; Ahmed, M.; Omeman, Z.; Whalen, J. Investigation of soil-geosynthetic-structure interaction associated with induced trench installation. Geotext. Geomembr. 2017, 45, 320-330. [CrossRef]

25. Meguid, M.; Ahmed, M.; Hussein, M.; Omeman, Z. Earth pressure distribution on a rigid box covered with u-shaped geofoam wrap. Int. J. Geosynth. Ground Eng. 2017, 3, 11. [CrossRef]

26. Zarnani, S.; Bathurst, R. Experimental investigation of EPS geofoam seismic buffers using shaking table tests. Geosynth. Int. 2007, 14, 165-177. [CrossRef]

27. Horvath, J.S. The compressible inclusion function of EPS geofoam. Geotext. Geomembr. 1997, 15, 77-120. [CrossRef]

28. Bathurst, R.J.; Keshavarz, A.; Zarnani, S.; Take, W.A. A simple displacement model for response analysis of EPS geofoam seismic buffers. Soil Dyn. Earthq. Eng. 2007, 27, 344-353. [CrossRef]

29. Ossa, A.; Romo, M. Dynamic characterization of EPS geofoam. Geotext. Geomembr. 2011, 29, 40-50. [CrossRef]

30. Partos, A.; Kazaniwsky, P. Geoboard reduces lateral earth pressures. In Proceedings of the Geosynthetics' 87 Conference, IFAI, New Orleans, LA, USA, 24-25 February 1987; pp. 628-639.

31. AbdelSalam, S.S.; Azzam, S.A. Reduction of lateral pressures on retaining walls using geofoam inclusion. Geosynth. Int. 2016, 23, 395-407. [CrossRef]

32. Azzam, S.A.; Shokry, B.M.; AbdelSalam, S.S. 3D Modeling of EPS Geofoam Buffers Behind Diaphragm Walls; Paper Presented at the GeoMEast 2017; Ground Improvement and Earth Structures-Sustainable Civil Infrastructures: Sharm El-Sheikh, Egypt, 2017; pp. 46-53.

33. Chauhan, V.B.; Dasaka, S.M. Assessment of Lateral Earth Pressure Reduction Using EPS Geofoam-A Numerical Study. Proceedings of Conference on Numerical Modeling in Geomechanics (CoNMiG-2017), IIT Roorkee, India, 3-4 March 2017; pp. 1-8, in CD (Paper ID-01).

34. Ertugrul, O.L.; Trandafir, A.C. Lateral earth pressures on flexible cantilever retaining walls with deformable geofoam inclusions. Eng. Geol. 2013, 158, 23-33. [CrossRef] 
35. Karpurapu, R.; Bathurst, R.J. Numerical investigation of controlled yielding of soil-retaining wall structures. Geotext. Geomembr. 1992, 11, 115-131. [CrossRef]

36. Hatami, K.; Witthoeft, A. A numerical study on the use of geofoam to increase the external stability of reinforced soil walls. Geosynth. Int. 2008, 15, 452-470. [CrossRef]

37. Trandafir, A.C.; Moyles, J.F.; Erickson, B.A. Finite-element analysis of lateral pressures on rigid non-yielding retaining walls with EPS geofoam inclusion. In Proceedings of the Earth Retention Conference, Bellevue, WA, USA, 1-4 August 2010 ; pp. 756-763.

38. Azzam, S.A.; AbdelSalam, S.S. EPS Geofoam to reduce lateral earth pressure on rigid walls. In Proceedings of the International Conference on Advances in Structural and Geotechnical Engineering, ICASGE'15, Hurghada, Egypt, 6-9 April 2015.

39. Hasanpouri, N.N.; Dabiri, R. Effects of geofoam panels on static behavior of cantilever retaining wall. Adv. Civil Eng. 2018, 2018, 2942689. [CrossRef]

40. Yadav, P.; Singh, D.K.; Dahale, P.P.; Padade, A.H. Analysis of retaining wall in static and seismic condition with inclusion of geofoam using Plaxis 2D. Geohazards 2021, 86, 223-240.

41. Ertugrul, O.L.; Trandafir, A.C. Reduction of lateral earth forces acting on rigid nonyielding retaining walls by EPS geofoam inclusions. Mater. Civ. Eng. 2011, 12, 1711-1718. [CrossRef]

42. Brinkgreve, R.; Broere, W. PLAXIS 2D Reference Manual 2015; Plaxis bv: Delft, The Netherlands, 2015.

43. Jaky, J. The coefficient of earth pressure at rest. J. Soc. Hung. Archit. Eng. 1944, 78, 355-358.

44. Khan, M.I.; Meguid, M. Experimental investigation of the shear behavior of EPS geofoam. Int. J. Geosynth. Ground Eng. 2018, 4, 12. [CrossRef]

45. Khan, M.I.; Meguid, M. Investigation of the Shear Behavior of EPS Geofoam. In Proceedings of the GeoEdmonton 2018-The 71st Canadian Geotechnical Conference, Edmonton, AB, Canada, 23-26 September 2018.

46. Meguid, M.A.; Khan, M.I. On the role of geofoam density on the interface shear behavior of composite geosystems. Int. J. Geo Eng. 2019, 10, 6. [CrossRef] 